\title{
MÉTODO DE ESTUDO DA ADSORÇÃO DE TRIADIMENOL COM MICRO-COLUNAS DE SOLO E CENTRIFUGAÇÃO
}

Mário César Guerreiro* e Alexandre dos Santos Anastácio

Departamento de Química, Universidade Federal de Lavras, CP 37, 37200-000 Lavras - MG

José Maria de Lima

Departamento de Ciência do Solo, Universidade Federal de Lavras, CP 37, 37200-000, Lavras - MG

Recebido em 15/4/03; aceito em 15/10/03

\begin{abstract}
METHOD FOR ADSORPTION STUDY OF TRIADIMENOL USING SOIL MICRO-COLUMNS AND CENTRIFUGATION. Normally, the determination of equilibrium constants $\left(\mathrm{k}_{\mathrm{d}}\right)$ in batch experiments uses a high solution to soil ratio, which does not represent field conditions. In this study we present an alternative method to evaluate adsorption constants, using micro-columns of soil at higher soil to solution ratios. The centrifugation force and equilibration time were investigated. The triadimenol distribution along the column profile is controlled by diffusion and equilibration times greater than $24 \mathrm{~h}$ are needed to achieve reproducibility. The centrifugation force must be superior to $670 \mathrm{~g}$ in order to guarantee enough extraction of the liquid solution from the soil columns.
\end{abstract}

Keywords: adsorption; soil column; triadimenol.

\section{INTRODUÇÃO}

A adsorção pode ser entendida como um fenômeno que ocorre na interface de duas fases, em que uma espécie química (adsorbato) se concentra na superfície de uma outra espécie química (adsorvente) com consequiente troca de calor $^{1,2}$.

Para o sistema solo, o adsorvente é representado pelas superfícies dos colóides do solo e o adsorbato corresponde a várias espécies químicas, entre elas, pesticidas. A adsorção é um dos processos limitantes do movimento dos pesticidas no solo, definindo, muitas vezes, a dose de produto a ser aplicada e o potencial de contaminação de mananciais hídricos. Uma baixa adsorção pode indicar uma grande mobilidade. Já uma adsorção alta pode interferir na disponibilidade do composto, implicando na aplicação de doses mais elevadas ${ }^{3}$.

A quantificação da adsorção é feita através de isotermas. Essas são a relação entre a quantidade de soluto adsorvido na superfície (x/m ou W) e a concentração em equilíbrio ${ }^{4}$. As isotermas podem ser obtidas a partir dos estudos de adsorção chamados equilíbrios em batelada ("batch equilibrium") 5 . Esses métodos empregam elevada relação solução-solo o que não reflete as condições de campo, onde, de fato, os produtos são aplicados. Além disso, podem levar a uma interpretação errônea do processo de adsorção, uma vez que as moléculas de água podem competir pelos sítios de adsorção do composto ${ }^{6}$.

$\mathrm{O}$ uso cada vez maior de defensivos nas grandes culturas tem sido causa de preocupação de diversos segmentos da sociedade, principalmente, quanto ao efeito no ambiente. No Brasil, por exemplo, a produção de café é muito importante, sendo um dos principais produtos de exportação. Uma das doenças mais comuns da cultura cafeeira é a ferrugem, causada pelo fungo Hemileia vastratrix Berk $\& \mathrm{Br}^{7,8}$. O combate dessa praga é feito com a aplicação de fungicidas sistêmicos, como o triadimenol (1). Esse composto é comprovadamente persistente no ambiente ${ }^{9-11}$ e sua interação com solos tropicais precisa ser mais investigada.

*e-mail: guerrero@ufla.br

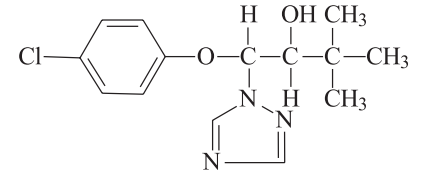

O objetivo do presente trabalho foi propor um método de avaliação da adsorção de pesticidas em solos. Para isto, foram utilizadas micro-colunas de solo, com relação solução:solo mais próxima às condições de campo (quantidade de solução suficiente para a saturação da amostra de solo), solução esta contendo o fungicida triadimenol. Foram ainda avaliadas as influências do tempo de equilíbrio e a da força centrífuga no estabelecimento do método, no sentido de validá-lo para uso futuro.

\section{PARTE EXPERIMENTAL}

O solo utilizado no experimento foi um Latossolo Vermelho Distrófico Típico (LE), representativo da região de Lavras, coletado em profundidade de 0 a $20 \mathrm{~cm}$.

A amostra de solo foi destorroada e seca ao ar livre e posteriormente passada em peneira de $2 \mathrm{~mm}$ de malha obtendo-se, portanto, a chamada terra fina seca ao ar (TFSA). A análise de solo foi feita ${ }^{12} \mathrm{e}$ alguns parâmetros químicos e físicos do solo são apresentados na Tabela 1.

Para a realização do experimento, foram utilizadas micro-colunas de solo com $6 \mathrm{~cm}$ de altura e $3,7 \mathrm{~cm}$ de diâmetro interno (Figura 1).

Nas colunas foram acondicionadas $50 \mathrm{~g}$ da amostra do solo. Em seguida, as colunas sem o dispositivo da coleta do lixiviado foram colocadas em recipientes contendo soluções de triadimenol com 1, 2, 5,10 e $20 \mathrm{mg} \mathrm{kg}^{-1}$, preparadas a partir de solução estoque de $500 \mathrm{mg} \mathrm{kg}^{-1}$ em água. O ensaio foi realizado em triplicata. A solução atingiu 2/3 da altura das colunas, sendo a amostra no interior das mesmas saturada por capilaridade. Para a avaliação da influência do tempo de equilíbrio, as colunas permaneceram nas soluções durante 12, 24 e $48 \mathrm{~h}$. Foram montadas ainda três colunas para a avaliação de recuperação do triadimenol e outras três para testemunha. Decorridos os respecti- 
Tabela 1. Resultado da análise do latossolo vermelho distrófico típico

\begin{tabular}{lccc}
\hline Elemento & Unidade & Resultado & Classificação \\
\hline pH em água (1:2,5) & - & 4,9 & Acidez Média \\
P (Mehlich I) & $\mathrm{mg} \mathrm{L}^{-1}$ & 1,0 & Baixo \\
K (Mehlich I) & $\mathrm{mg} \mathrm{L}^{-1}$ & 20,0 & Baixo \\
$\mathrm{Ca}$ & $\mathrm{cmol}_{\mathrm{c}} \mathrm{dm}^{-3}$ & 0,2 & Baixo \\
$\mathrm{Mg}$ & $\mathrm{cmol} \mathrm{dm}_{\mathrm{c}} \mathrm{dm}^{-3}$ & 0,1 & Baixo \\
$\mathrm{Al}$ & $\mathrm{cmol}_{\mathrm{c}} \mathrm{dm}^{-3}$ & 0,9 & Médio \\
$\mathrm{H}+\mathrm{Al}$ & $\mathrm{cmol} \mathrm{dm}_{\mathrm{c}}^{-3}$ & 9,8 & Alto \\
Matéria Orgânica & $\mathrm{g} \mathrm{kg}^{-1}$ & 41 & Alto \\
Areia & $\mathrm{g} \mathrm{kg}^{-1}$ & 240 & \\
Silte & $\mathrm{g} \mathrm{kg}^{-1}$ & 70 & \\
Argila & $\mathrm{g} \mathrm{kg}^{-1}$ & 690 & \\
\hline
\end{tabular}

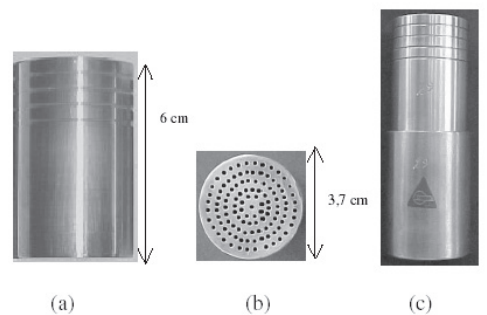

Figura 1. Ilustração da micro-coluna empregada para centrifugação: (a) vista lateral da coluna onde a amostra de solo é acondicionada; (b) vista do fundo da coluna com orifícios para drenagem da solução efluente; (c) coluna montada para centrifugação com a base para coleta da solução efluente

vos tempos de equilíbrio, as colunas saturadas foram pesadas para avaliação da massa de solução saturante e centrifugadas a $670 \mathrm{~g} \mathrm{du}-$ rante $10 \mathrm{~min}$. Após centrifugação, as colunas foram novamente pesadas para avaliação da massa de solução retida nas mesmas. A solução efluente (cerca de $10 \mathrm{~mL}$ ) foi recolhida e o triadimenol foi recuperado por extração líquido-líquido. Para a extração, foram adicionados 5 $\mathrm{mL}$ de acetona à fase aquosa, para a quebra da emulsão. Em seguida, $5 \mathrm{~mL}$ de diclorometano foram adicionados e a mistura foi agitada por 1 min a cada nova adição de diclorometano (três vezes). A fase orgânica foi seca com sulfato de sódio anidro. As três frações foram evaporadas até a secura em um evaporador rotativo. O resíduo de triadimenol foi recuperado com acetona e quantificado por cromatografia a gás. Para isso, foi utilizado cromatógrafo a gás (HP - série 6890), equipado com detector de captura de elétrons, a $300{ }^{\circ} \mathrm{C}$, com injetor "split/ splitless" em temperatura de $250^{\circ} \mathrm{C}$ no modo "splitless". O forno foi mantido nas seguintes condições: temperatura inicial de $100{ }^{\circ} \mathrm{C}$, permanecendo $1 \mathrm{~min}$; rampa de aquecimento de $30^{\circ} \mathrm{C} / \mathrm{min}$; temperatura final de $280^{\circ} \mathrm{C}$, permanecendo $2 \mathrm{~min}$. $\mathrm{O}$ gás de arraste foi o nitrogênio a $1,5 \mathrm{~mL} / \mathrm{min}$. Foi utilizada coluna cromatográfica HP-5, com $30 \mathrm{~m}$ x $320 \mu \mathrm{m}$ x 0,25 $\mu \mathrm{m}$ e $5 \%$ de fenil-metil-siloxano. O volume injetado de amostra foi $1,0 \mu \mathrm{L}$, por $60 \mathrm{~s}$.

A quantificação foi feita através de padronização externa e curvas analíticas. A recuperação do fungicida foi feita com soluções aquosas fortificadas contendo $1 \mathrm{mg} \mathrm{kg}^{-1}$ de triadimenol.

No estudo da influência da força de centrifugação, o tempo de equilíbrio foi de $24 \mathrm{~h}$ para as três acelerações estudadas. Após o equilíbrio de $24 \mathrm{~h}$, as colunas foram pesadas e centrifugadas a 168 , 670 e 1500 g em uma Centrífuga Jouan C 312. Foram então repetidos os processos de pesagem das colunas, de coleta da fase aquosa, de extração líquido-líquido e quantificação do triadimenol.

Foi ainda realizado o estudo da distribuição do triadimenol ao longo das colunas. Para tal, as colunas de solo foram equilibradas com as soluções de menor e maior concentrações utilizadas neste estudo (1 e $20 \mathrm{mg} \mathrm{kg}^{-1}$, correspondendo à solução final de triadimenol nas colunas de 23,5 e 214,7 $\mathrm{mg} \mathrm{kg}^{-1}$ ), sendo o tempo de equilíbrio de $24 \mathrm{~h}$. O experimento foi feito em triplicata. Decorrido este tempo, as colunas foram centrifugadas a $670 \mathrm{~g}$ durante $10 \mathrm{~min}$. As colunas de solo, imediatamente após a centrifugação, foram manualmente separadas em quatro camadas de $1,5 \mathrm{~cm}$.

Ao material de cada camada foram adicionados $50 \mathrm{~mL}$ de uma solução extratora, consistindo de água e acetona em proporção de 1:3 em volume. A mistura permaneceu sob agitação durante $1 \mathrm{~h}$. Em seguida, a suspensão foi centrifugada a $670 \mathrm{~g}$ durante $10 \mathrm{~min}$. $\mathrm{O}$ extrato foi levado a evaporador rotativo para redução de volume aproximadamente de $10 \mathrm{~mL}$, que foi então submetido ao processo de extração e quantificação do triadimenol.

\section{RESULTADOS E DISCUSSÃO}

A recuperação do triadimenol, empregando-se o processo de extração descrito, foi de $90 \%$. Este valor está de acordo com dados da literatura que descrevem que a recuperação deste composto varia de 70 a $100 \%$ em diferentes matrizes, incluindo solos ${ }^{13}$.

As isotermas de adsorção, obtidas pelo método descrito, em função do tempo de equilíbrio são apresentadas na Figura 2. Verifica-se um bom ajuste linear dos dados para os tempos de equilíbrio de $24 \mathrm{e}$ 48 h. Para 12 h, o resultado apresenta um maior desvio em relação à linearidade.

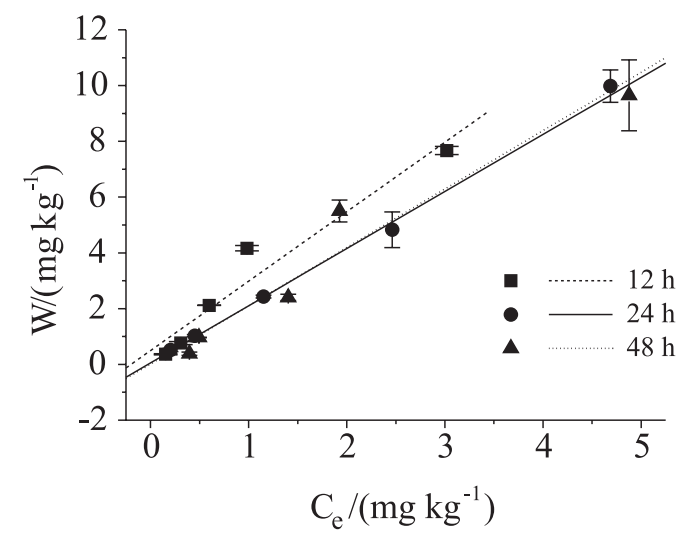

Figura 2. Isoterma de adsorção $(T=298 \mathrm{~K})$ do triadimenol em Latossolo Vermelho Distrófico Típico para diferentes tempos de equilíbrio

Os dados de adsorção ajustados por regressão linear (método dos quadrados mínimos) são apresentados na Tabela 2.

Os parâmetros encontrados mostram que a adsorção do triadimenol, no intervalo de concentração estudado, apresenta uma isoterma linear para os tempos de 24 e $48 \mathrm{~h}$, sendo, portanto, do tipo C ${ }^{14}$. A análise de variância mostrou que, para a probabilidade de erro de 5\%, as concentrações recuperadas de triadimenol para o tempo de $12 \mathrm{~h}$ diferiram dos tempos de $24 \mathrm{e} 48 \mathrm{~h}$.

Tabela 2. Coeficientes de partição do triadimenol em amostras de Latosssolo Vermelho Distrófico Típico sob diferentes tempos de equilíbrio

\begin{tabular}{lcc}
\hline Tempo/h & $\mathrm{k}_{\mathrm{d}}$ & $\mathrm{R}^{2}$ \\
\hline 12 & $2,49 \pm 0,45^{\mathrm{a}}$ & 0,941 \\
24 & $2,10 \pm 0,08^{\mathrm{a}}$ & 0,998 \\
48 & $2,05 \pm 0,34^{\mathrm{a}}$ & 0,950 \\
\hline
\end{tabular}

a: intervalo de confiança $\left( \pm \frac{\text { s.t }}{\sqrt{n}}\right)$, em que s: estimativa de desviopadrão, teste t para probabilidade de $95 \%$ e n: número de observações. 
A cinética de adsorção do triadimenol caracteriza-se por apresentar dois estágios, sendo um rápido: cerca de $4 \mathrm{~h}^{15}$ que é predominantemente superficial (dependente da disponibilidade de sítios ativos). Em seguida, ocorre um processo lento, através da difusão e migração do soluto. Isso pode ser observado para o experimento de $12 \mathrm{~h}$, em que o processo de difusão ainda não se completou, ficando evidenciado um efeito do transporte de massas na forma da isoterma encontrada nesse tempo de equilíbrio. A boa correlação dos dados obtida nos tempos de 24 e 48 h mostra que o efeito de transporte de massas atuando na adsorção já não é tão significativo, e que o processo de difusão está praticamente em equilíbrio. Para esses tempos de equilíbrio, observaram-se isotermas lineares, uma vez que as concentrações de triadimenol utilizadas são baixas.

Os valores da constante de partição $\left(\mathrm{k}_{\mathrm{d}}\right)$ e os respectivos valores de $\mathrm{R}^{2}$ para as diferentes forças de centrifugação são apresentados na Tabela 3. Na Figura 3 são mostradas as isotermas obtidas em função da força centrífuga, ajustadas por regressão linear.

Tabela 3. Coeficiente de partição do triadimenol em amostras de Latossolo Vermelho Distrófico Típico sob diferentes forças de centrifugação

\begin{tabular}{lcc}
\hline Força/g & $\mathrm{k}_{\mathrm{d}}$ & $\mathrm{R}^{2}$ \\
\hline 168 & $0,82 \pm 0,14^{\mathrm{a}}$ & 0,945 \\
670 & $2,10 \pm 0,08^{\mathrm{a}}$ & 0,998 \\
1500 & $1,19 \pm 0,21^{\mathrm{a}}$ & 0,991 \\
\hline
\end{tabular}

a: intervalo de confiança $\left( \pm \frac{\text { s.t }}{\sqrt{n}}\right)$, em que s: estimativa de desviopadrão, teste t para probabilidade de $95 \%$ e n: número de observações.

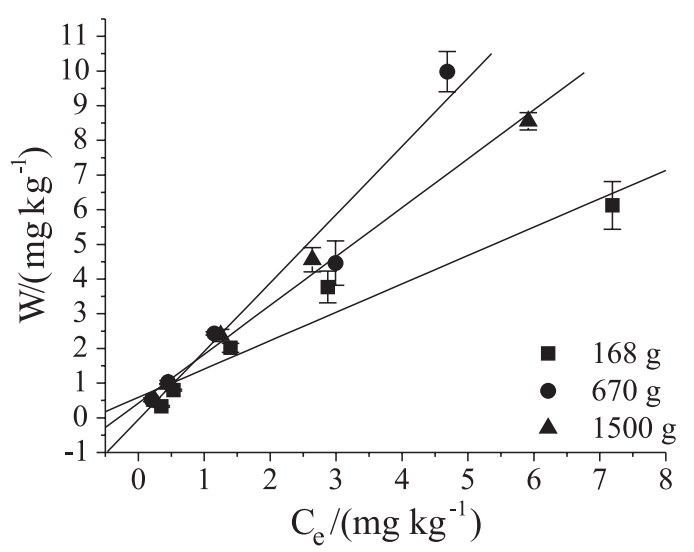

Figura 3. Isoterma de adsorção $(T=298 \mathrm{~K})$ do triadimenol em amostras de Latossolo Vermelho Distrófico Típico sob diferentes forças de centrifugação

O aumento da força centrífuga aumenta o volume de solução efluente, melhorando significativamente a qualidade dos dados. Os resultados da análise de variância indicaram que a força de $168 \mathrm{~g}$ propiciou concentração de triadimenol inferior às concentrações recuperadas nas rotações de 670 e $1500 \mathrm{~g}$, para probabilidade de erro de $5 \%$. A força centrífuga para a extração da solução compete com a força matricial da amostra de solo para a retenção da mesma. Quanto mais próximo da superfície das partículas, maior a força matricial e, também, maior a concentração do produto, considerando-se que o triadimenol apresenta maior afinidade pela matéria orgânica presente no substrato do que pela solução aquosa ${ }^{8}$. Dessa forma, maior força de centrifugação representa maior concentração do produto na solução efluente.
Na Figura 4 são mostrados os percentuais de água retida no solo em função das acelerações de centrifugação. Observa-se que a menor força de centrifugação possui uma capacidade para a retirada de solução do solo inferior às demais rotações empregadas. A capacidade de retirada de solução do solo é semelhante para as forças de 670 e 1500 g. A retirada da solução residual influência no valor de $\mathrm{k}_{\mathrm{d}}$ calculado.

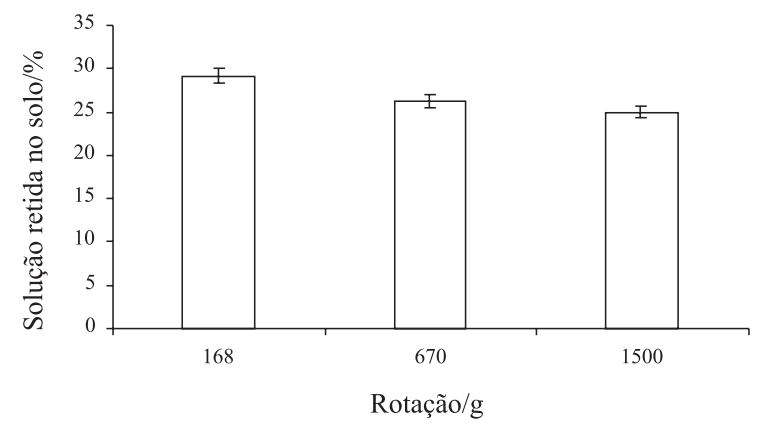

Figura 4. Quantidade de solução retida no solo após centrifugação em diferentes forças de centrifugação

Assim, há uma correlação entre o valor de $\mathrm{k}_{\mathrm{d}}$ obtido e a capacidade de retirada do efluente do solo, indicando que uma força igual ou superior a $670 \mathrm{~g}$ deve ser empregada para garantir a reprodutibilidade dos resultados.

A distribuição do triadimenol na coluna de amostra estudada, analisando-se a quantidade da substância em quatro camadas para duas concentrações e tempo de equilíbrio de 24 h, é apresentada em porcentagem de triadimenol relativamente à quantidade retida na amostra, após a centrifugação na força de 670 g. Esses dados são apresentados na Figura 5.

Distribuição do triadimenol nas camadas
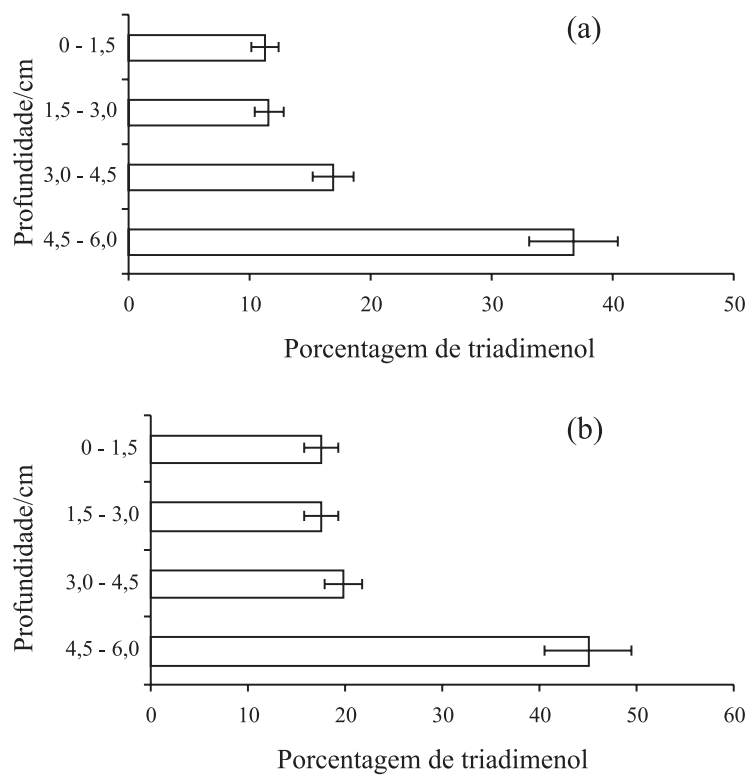

Figura 5. Distribuição do triadimenol na coluna de amostra de solo para: (a) $23,5 \mathrm{mg} \mathrm{kg}^{-1}$ e (b) $214,7 \mathrm{mg} \mathrm{kg}^{-1}$

A distribuição do triadimenol nas camadas da amostra indica que o composto é retido principalmente na camada de 4,5 a $6 \mathrm{~cm}$. Observa-se para todas as camadas uma distribuição bastante semelhante para as duas concentrações, mostrando que o processo está em equilíbrio após $24 \mathrm{~h}$. 
Esses resultados corroboram para a validação do método, pois uma distribuição uniforme do pesticida ao longo do perfil da coluna, para suas diferentes concentrações, é essencial para garantir a reprodutibilidade do método.

\section{CONCLUSÕES}

$\mathrm{O}$ procedimento de determinação de $\mathrm{k}_{\mathrm{d}}$ por micro-colunas de solo mostrou-se adequado, apresentando boa reprodutibilidade para o estudo da adsorção de triadimenol em amostra de solo Latossolo Vermelho Distrófico Típico. O emprego desse método para outros pesticidas passa pela necessidade de determinar o tempo de equilíbrio adequado, pois há uma etapa governada por difusão, que depende do tipo de substância estudada. A recuperação do lixiviado por centrifugação deve ser realizada empregando-se uma força centrífuga adequada, para garantir que a quantidade efluente retirada da coluna seja uniforme.

\section{REFERÊNCIAS}

1. Atkins, P. W.; Físico-Química, 6 ed., LTC-Livros Técnicos e Científicos: Rio de Janeiro, 1999, vol. 3.
2. Dabrowski, A.; Adv. Colloid Interface Sci. 2001, 93, 135.

3. Day, B. E.; Jordan, L. S.; Jolliffe, V. A.; Weed Sci. 1968, 16, 209.

4. Sposito, G.; The Chemistry of Soils, Oxford University Press: New York, 1989.

5. Instituto Brasileiro do Meio Ambiente e dos Recursos Renováveis; Manual de Teste para Avaliação da Ecotoxicidade de Agentes Químicos, 2 ed., Brasília: 1990.

6. Koskinen, W.C.; Harper, S. S. Em Pesticides in Soil Environment: processes, impacts, and modeling; Cheng, H. H., ed.; SSSA: Madison, 1990, p. 51.

7. Oliveira, A. M. de; Dissertação de Mestrado, Universidade Federal de Viçosa, Brasil, 1999.

8. Lopes, N. P.; Dissertação de Mestrado, Universidade Federal de Viçosa, Brasil, 1999.

9. http://wizard.arsusda.gov/acsl/textfiles/TRIADIMENOL, acessada em Outubro 2001.

10. Bromilow, R. H.; Evans, A. A.; Nicholls, P. H.; Pest. Sci. 1999, 55, 1129.

11. Bromilow, R. H.; Evans, A. A.; Nicholls, P. H.; Pest. Sci. 1999, 55, 1135.

12. Empresa Brasileira de Pesquisa Agropecuária; Manual de Métodos de Análise de solo, 2. ed., Rio de Janeiro, 1997.

13. Specht, W.; Pflamzenschutz Nachrichten Bayer 1977, 30, 55

14. Giles, C. H.; McEwan, T. H.; Nakhwa, S. N.; Smith, D.; J. Chem. Soc. 1960, 3, 3973.

15. Gao, J. P.; Maguhn, J.; Spitzauer, P.; Ketrup, A.; Water Res. 1998, 32, 1622. 